\title{
Canadian Urological Association position statement on the use of transvaginal mesh
}

\author{
Blayne Welk, MD'; Kevin V. Carlson, MD2; Richard J. Baverstock, MD ${ }^{2,3}$; Stephen S. Steele, MD'; \\ Gregory G. Bailly, $M D^{5}$; Duane R. Hickling, $M D^{6}$
}

'Department of Surgery, Western University, London, ON; ${ }^{2}$ Section of Urology, Department of Surgery, University of Calgary, Calgary, AB; ${ }^{3}$ vesia [Alberta Bladder Centre], Calgary, AB; ${ }^{4}$ Queen's University, Kingston, ON; ${ }^{D}$ Department of Urology, Dalhousie University, Halifax, NS; ${ }^{6}$ Division of Urology, Department of Surgery, The Ottawa Hospital, Ottawa, ON; Canada

Cite as: Can Urol Assoc J 2017;11 (6Suppl2):S105-7. http://dx.doi.org/10.5489/cuaj.4579

\section{Abstract}

Stress incontinence (SUI) and pelvic organ prolapse (POP) are common conditions. There is high-level evidence that midurethral mesh slings for stress incontinence are effective and safe; however, the rare but serious potential risks of this surgery must be discussed with the patient. The use of transvaginal mesh for prolapse repair does not appear to be supported by the current evidence, and its use should be restricted to specialized pelvic floor surgeons and specific clinical situations.

\section{Introduction}

Stress urinary incontinence (SUI) and pelvic organ prolapse (POP) are common conditions that can have a negative impact on a patient's quality of life. An estimated one in five women will undergo surgical treatment for one of these problems in their lifetime. ${ }^{1}$ Based on the successful use of synthetic mesh in other surgical fields, transvaginal mesh procedures were developed to treat both SUI and POP. The initially reported advantages associated with transvaginal mesh procedures included a reduced operative time, shorter hospital stay, and quicker patient recovery. In addition, these procedures were initially thought to provide a more consistently effective and durable surgical result. ${ }^{2}$

In the mid-1990s, transvaginal synthetic mesh sling procedures for SUI were developed. In these procedures, surgeons place a long narrow strip of mesh under the urethra in a tension free manner using trocars passed via the retropubic or transobturator route. In principle, these slings are meant to provide a backboard of support which allows for appropriate urethral coaptation during activities that increase intraabdominal pressure such as cough, sneeze, laugh or physical exertion. Transvaginal mesh kits for prolapse were developed in the early 2000 s to reduce compartmental pel- vic prolapse by recreating normal pelvic floor supports via placement of a square or trapezoidal sheet of mesh, which is held in place with transvaginal "arms" placed with the aid of specially designed trocars.

Health Canada issued a Notice to Hospitals in 2010 (and updated in 2014) regarding the use of transvaginal mesh for the treatment of female SUI and POP. The statement regarding the use of transvaginal mesh for prolapse states that there may be a higher rate of complications compared to traditional operations, which do not use synthetic mesh. The statement regarding the use of transvaginal mesh for prolapse and stress incontinence specified that these procedures may lead to complications, which may not be fully correctable with additional surgery, and that surgeons should have adequate training in transvaginal mesh and be familiar with the device warnings and techniques. ${ }^{3}$

Regulatory warnings, media interest, and high-profile stories of patient complications have led to widespread awareness of the potential negative aspects of transvaginal mesh. Often the distinction between the different procedures involving transvaginal mesh is not clear, leading to confusion among patients. ${ }^{4}$

\section{CUA position regarding the use of transvaginal mesh for female SUI}

An extensive body of literature supports the routine use of full length transvaginal retropubic or transobturator mesh slings for SUI. This procedure is common, appropriate for almost any patient with SUI, and is the most commonly performed SUI procedure in North America. Studies have suggested that these procedures are generally as effective, or sometimes more effective than traditional SUI operations. ${ }^{5}$

Rare, but serious complications such as injury to other structures during trocar passage, intraoperative placement or post-operative migration of the mesh into the urethra or 
Welk et al.

bladder, and vaginal or pelvic pain have been reported. These outcomes may not be fully correctable even with additional surgery. ${ }^{6}$ Serious adverse events, such as ureteral injury, fistula, pelvic pain, and wound complications requiring reoperation, can also occur with traditional nonmesh-based SUI procedures. ${ }^{7}$ A recent study comparing the risks of mesh midurethral slings and traditional non-mesh SUI procedures demonstrated that early surgical complications are lower after midurethral sling and late complications requiring reoperation are similar. ${ }^{8}$ Transvaginal mesh slings should not be used in women with urethral diverticulum, urethrovaginal fistula, urethral injury, or prior transvaginal mesh complication (such as pain or mesh erosion).

Numerous organizations support the use of full-length midurethral mesh slings for SUI, including the American College of Obstetricians and Gynecologists, the American Urogynecologic Society, the International Urogynecological Association, the Society of Urodynamics, Female Pelvic Medicine and Urogenital Reconstruction, and the American Urology Association. ${ }^{9,10}$ Further evidence is required before a statement applicable to non-full-length transvaginal mesh sling (such as the shorter "mini-slings") can be made.

\section{Recommendations for surgeons placing transvaginal mesh for female SUI}

When a transvaginal SUI procedure is offered to a patient, they must be informed of potential procedure-specific and mesh-specific complications. The 2014 Health Canada Advisory should be disclosed to patients. Surgeons performing these procedures should be adequately trained in SUI surgery and specifically trained in the sling technique they use. They should be capable of recognizing, diagnosing, and treating potential mesh-related complications associated with their procedure.

\section{CUA position statement regarding the use of transvaginal mesh for POP}

The currently available literature does not support the routine use of transvaginal mesh for prolapse repair. This recommendation does not apply to the use of transabdominal mesh used during a minimally invasive or open sacrocolpopexy. Although fewer women have symptomatic prolapse after transvaginal mesh repair compared to traditional repairs, the magnitude of this difference is small. ${ }^{11}$ In addition, women have an over two-fold higher risk of additional surgery, primarily from the unique risk of mesh removal or revision. The treatment of these complications is often technically challenging and may not fully correct the associated symptoms. ${ }^{12}$ Studies from both Canada and U.S. suggest that the use of transvaginal mesh procedures for POP is becoming less common. ${ }^{13,14}$ A recent randomized clinical trial compared mesh and non-mesh transvaginal prolapse repair and found that there was no difference in objective or subjective outcomes, and that 1/10 patients who had mesh-augmented repairs had secondary surgery for mesh complications. ${ }^{15}$ Placement of transvaginal mesh may still be indicated in select cases; for example, in the setting of recurrent prolapse in which an abdominal sacrocolpopexy is contraindicated.

Other organizations have also suggested that the routine use of transvaginal mesh for prolapse repair is not warranted (such as the Royal College of Obstetricians and Gynaecologists, the British Society of Urogynaecology, and the American College of Obstetricians and Gynecologists), and the US Food and Drug Administration has classified transvaginal mesh used for prolapse as a high-risk device and has required additional safety studies within the next three years.

\section{Recommendations for surgeons placing transvaginal mesh for prolapse}

When a transvaginal prolapse procedure is offered to patients, they must be informed of potential procedurespecific and mesh-specific complications, and the rationale for the use of mesh should be explained. The 2014 Health Canada advisory should be disclosed to patients. Surgeons performing these procedures should be adequately trained in pelvic floor reconstructive surgery, including the use of specific transvaginal synthetic mesh prolapse kits. They should be capable of diagnosing and treating potential mesh-related complications associated with their procedure.

Competing interests: Dr. Welk has received investigator-initiated funding from Astellas. Dr. Carlson and Dr. Baverstock have been advisors and speakers for, and have received honoraria from Allergan. Dr. Steele has been an advisor for Allergan, Astellas, Fering, and Pfizer; a speaker for Abbott, Astellas, and Pfizer; has received grants from Astellas and Pfizer; and has participated in clinical trials supported by Astellas and Pfizer. Dr. Bailly has been an advisor and speaker for, has received honoraria from, and has participated in clinical trrials supported by Allergan, Astellas, and Pfizer. Dr. Hickling has been a speaker for Allergan, Astellas, and Pfizer; and has participated in clinical trials supported by Astellas and Ipsen.

This paper has been peer reviewed.

\section{References}

1. Wu JM, Mathews $C A$, Conover MM, et al. Lifetime risk of stress urinary incontinence or pelvic organ prolapse surgery. Obstet Gynecol 2014;123:1201-6. https://doi.org/10.1097/A0G.0000000000000286

2. Brophy MM, Klutke JJ, Klutke CG. A review of the tension-free vaginal tape procedure: Outcomes, complications, and theories. Curr Urol Rep 2001;2:364-9. https://doi.org/10.1007/s1 1934-996-0021-1 
3. Surgical mesh - Complications associated with transvaginal implantation for the treatment of stress urinary incontinence and pelvic organ prolapse - notice to hospitals - recalls \& alerts 2014 - Healthy Canadians website. www.healthycanadians.gc.ca. http://www.healthycanadians.gc.ca/recall-alert-rappel-avis/hcsc/2014/39475a-eng.php. Published May 13, 2014. Accessed March 5, 2015.

4. Brown LK, Fenner DE, Berger MB, et al. Defining patients' knowledge and perceptions of vaginal mesh surgery. Female Pelvic Med Reconstr Surg 2013;19:282-7. https://doi.org/10.1097/ SPV.0b013e31829ff765

5. Schimpf $M 0$, Rahn DD, Wheeler TL, et al. Sling surgery for stress urinary incontinence in women: A systematic review and meta-analysis. Am J Obstet Gynecol 2014;211:71-e27. https://doi.org/10.1016/i. ajog.2014.01.030

6. Daneshgari F, Kong W, Swartz M. Complications of mid urethral slings: Important outcomes for future clinical trials. J Urol 2008;180:1890-7. https://doi.org/10.1016/i.juro.2008.07.029

7. Albo ME, Richter HE, Brubaker $L$, et al. Burch colposuspension vs. fascial sling to reduce urinary stress incontinence. N Engl J Med 2007;356:2143-55. https://doi.org/10.1056/NEJMoa070416

8. Morling JR, McAllister DA, Agur W, et al. Adverse events after first, single, mesh and non-mesh surgical procedures for stress urinary incontinence and pelvic organ prolapse in Scotland, 1997 2016: A populationbased cohort study. Lancet 2017;389:629-40. https://doi.org/10.1016/S0140-6736(16)32572-7

9. AUA position statement on the use of vaginal mesh for the surgical treatment of stress urinary incontinence (SUI): American Urological Association. https://www.auanet.org/education/vaginal-mesh-for-pelvicorgan-prolapse.fm. Accessed March 5, 2016.
10. AUGS/SUFU position statement on mesh midurethral slings for stress urinary incontinence. http://sufuorg.com/docs/news/augs-sufu-mus-position-statement.aspx. Accessed June 5, 2016.

11. Maher $C$, Feiner B, Baessler $\mathrm{K}$, et al. Transvaginal mesh or grafts compared with native tissue repair for vaginal prolapse. Cochrane Database Syst Rev 2016;2:CD012079-CD012079. https://doi.org/10.1002/14651858.CD012079

12. Menchen LC, Wein AJ, Smith AL. An appraisal of the Food and Drug Administration warning on urogynecological surgical mesh. Curr Urol Rep 2012;13:231-9. htrps://doi.org/10.1007/s1 1934-012-0244-2

13. Kelly $\mathrm{EC}$, Winick-Ng J, Welk B. Surgeon experience and complications of transvaginal prolapse mesh. Obstet Gynecol 2016;128:65-72. https://doi.org/10.1097/AOG.0000000000001450

14. Jacoby VL, Subak L, Waetjen LE. The FDA and the vaginal mesh controversy — further impetus to change the 510(k) pathway for medical device approval. JAMA Intern Med 2016;176:277-8. https://doi.org/10.1001/jamainternmed.2015.7155

15. Glazener $C M$, Breeman $S$, Elders $A$, et al. Mesh, graft, or standard repair for women having primary transvaginal anterior or posterior compartment prolapse surgery: Two parallel-group, multicentre, randomized, controlled trials (PROSPECT). Lancet 2017;389(10067):381-92. https://doi.org/10.1016/ S0140-6736(16)31596-3

Correspondence: Dr. Blayne Welk, Department of Surgery, Western University, London, ON, Canada; bkwelk@gmail.com 